\title{
Physical inactivity is an independent risk factor for hip fracture in the elderly
}

\author{
Carol Coupland, David Wood, Cyrus Cooper
}

\begin{abstract}
Study objective-To test the hypothesis that physical inactivity is an independent risk factor for hip fracture in the elderly. Design-Population based, case-control study.

Setting-Metropolitan borough of Newcastle upon Tyne.

Participants-A total of 197 patients aged 50 years and over, resident in Newcastle, and admitted consecutively with a hip fracture, and 382 community controls, matched by age and sex, who had not suffered a hip fracture. Measurements and main results-Validated methods were used to assess customary physical activity. Information on body build, cigarette smoking, and alcohol consumption was also obtained. Grip strength was measured. Physical inactivity was strongly associated with the risk of hip fracture in men and women. Subjects who did not regularly weight-bear, perform muscleloading activities such as climbing stairs, and perform productive activities such as gardening, were all more than twice as likely to sustain a hip fracture, when compared with subjects at the higher end of the activity spectrum. These increases in risk remained after adjusting for body mass index, smoking, alcohol consumption, and dependence in daily living activities.

Conclusions-Customary physical inactivity is an independent determinant of hip fracture in the elderly. Strategies to improve the day to day activity of elderly people require urgent exploration.
\end{abstract}

MRC Environmental Epidemiology Unit,

University of

Southampton,

Southampton General

Hospital,

Southampton

C Coupland

C Cooper

The University

Department of

Orthopaedic Surgery,

Royal Victoria

Infirmary, Newcastle

upon Tyne

D Wood

Correspondence to: Carol Coupland

Department of Public Health Medicine and Epidemiology, University of Nottingham Medical School, Queen's Medical Centre, Nottingham NG7 2UH

Accepted for publication June 1993 f Epidemiol Community Health 1993; 47: 441-443

Hip fractures in the elderly constitute a major public health problem for which preventive strategies are urgently required. ${ }^{1}$ The risk of hip fracture depends upon two ultimate determinants: bone strength and the risk of falling. ${ }^{2}$ Evidence is accumulating that physical activity is a determinant of bone density, ${ }^{3}$ and that regular weight-bearing exercise retards bone loss in middle and later life. ${ }^{+}$This has been supplemented by the results of two recent epidemiological studies of hip fracture in southern England ${ }^{5}$ and Hong Kong, ${ }^{6}$ in both of which customary physical inactivity was found to be an independent risk factor for hip fracture. To confirm this association, and to explore whether differences in activity patterns in elderly people might explain regional differences in the hip fracture incidence rate, we report a case-control study of hip fracture in Newcastle upon Tyne, a city in the northeast of England characterised by relatively high incidence rates for hip fracture. ${ }^{7} 8$

\section{Patients and methods}

We recruited 312 patients aged 50 years and over who lived in the metropolitan borough of Newcastle upon Tyne and were admitted to either of the two orthopaedic units serving the borough during 1987-88 after a hip fracture. Nine patients died before they could be approached. The remaining 303 completed a 10 point abbreviated mental test score,${ }^{9}$ and the $197(65 \%)$ who scored six points or more became the study cases.

Patients in the study group were compared with 382 community controls, resident in the same district, who were selected from the Newcastle Family Practitioner Committee register. Two controls were individually matched to each case by sex and age within four years. For 12 cases it was possible to find only one control. The response rate in controls was $74 \%$ of those contacted. When a control refused to participate or failed the mental test score, a substitute was selected.

All cases and controls were interviewed by a single nurse interviewer using a structured questionnaire. Cases were interviewed in hospital within 10 days of admission. Physical activity in the six weeks before the interview was estimated with a validated questionnaire for the assessment of customary activity in the elderly, as previously described. ${ }^{10}$ Five summary indices of physical activity were used: amount of time spent standing indoors, amount of time spent walking outdoors, self reported walking speed, frequency of stair climbing, and duration of outdoor productive activities, for example gardening, cleaning, and house repair work. These types of activity all involve significant amounts of time spent weightbearing, and comprise a substantial portion of the total activity undertaken by elderly people in Britain. ${ }^{10}$ Information was also obtained on body build, cigarette smoking, alcohol consumption, dietary calcium intake, medical and drug history, dependence in daily living activities, and reproductive variables in women. Grip strength was measured with an isometric dynamometer. The maximum of three readings on each hand was used for subsequent analysis.

The data were analysed using conditional logistic regression for matched case-control studies. ${ }^{11}$ A case-control set was excluded if either the information for the case or both controls was not available. The significance of gradients of odds ratios was assessed with $\chi^{2}$ tests for linear trend, using the original values of continuous variables as 
recorded. Relationships between variables were studied with multiple linear regression, or multiple logistic regression as appropriate.

\section{Results}

Table I shows the age and sex distribution of the 197 patients with hip fractures included in the study. Most of them (65\%) were greater than 75 years of age, and $168(85 \%)$ were women.

Table II shows the change in fracture risk with declining level of customary physical activity for men and women combined. There was a statistically significant $(p<0.01)$ increase in fracture risk with declining level of customary activity in four of the five indices, after adjustment was made for three potential confounding variables (body mass index, cigarette smoking, and alcohol consumption). The risk gradient was most marked for

Table I Distribution of 197 patients with hip fracture by age and sex

\begin{tabular}{lcccccc}
\hline Age group $(y)$ & $\begin{array}{l}\text { Men } \\
\text { No }\end{array}$ & $(\%)$ & $\begin{array}{l}\text { Women } \\
\text { No }\end{array}$ & $(\%)$ & \multicolumn{1}{c}{ Total } & No \\
\hline$<55$ & 2 & $(6 \cdot 9)$ & - & & 2 & $(1 \cdot 0)$ \\
$55-64$ & 5 & $(17 \cdot 2)$ & 11 & $(6 \cdot 5)$ & 16 & $(8 \cdot 1)$ \\
$65-74$ & 7 & $(24 \cdot 1)$ & 44 & $(26 \cdot 2)$ & 51 & $(25 \cdot 9)$ \\
$75-84$ & 9 & $(31 \cdot 0)$ & 67 & $(39 \cdot 9)$ & 76 & $(38 \cdot 6)$ \\
$85+$ & 6 & $(20 \cdot 7)$ & 46 & $(27 \cdot 4)$ & 52 & $(26 \cdot 4)$ \\
Total & 29 & $(14 \cdot 7)$ & 168 & $(85 \cdot 3)$ & 197 & \\
\end{tabular}

Table II Customary physical activity and the risk of hip fracture in cases and community controls matched by age and sex*

\begin{tabular}{|c|c|c|c|c|c|c|c|}
\hline Activity & Category & $\begin{array}{l}\text { No of } \\
\text { Cases }\end{array}$ & Controls & $\begin{array}{l}\text { Odds } \\
\text { ratiot }\end{array}$ & $(95 \% C I)$ & $\begin{array}{l}\text { Odds } \\
\text { ratio } \neq\end{array}$ & $(95 \% C I)$ \\
\hline $\begin{array}{l}\text { Standing } \\
\text { (min/day) }\end{array}$ & $\begin{array}{l}<120 \\
120-179 \\
180-239 \\
>239 \\
\text { Test for trend }\end{array}$ & $\begin{array}{l}86 \\
29 \\
28 \\
54\end{array}$ & $\begin{array}{r}78 \\
58 \\
63 \\
183\end{array}$ & $\begin{array}{l}9 \cdot 2 \\
3 \cdot 7 \\
1 \cdot 7 \\
1 \cdot 0 \\
x_{1}^{2}=42 \cdot 6 \\
p<0 \cdot 001\end{array}$ & $\begin{array}{l}(4 \cdot 3,19 \cdot 8) \\
(1 \cdot 8,7 \cdot 7) \\
(0 \cdot 9,3 \cdot 5) \\
-\end{array}$ & $\begin{array}{l}7 \cdot 1 \\
3 \cdot 2 \\
1 \cdot 6 \\
1 \cdot 0 \\
\chi^{2}=25 \cdot 1 \\
p<0 \cdot 001\end{array}$ & $\begin{array}{l}(2 \cdot 9,17 \cdot 0) \\
(1 \cdot 5,7 \cdot 0) \\
(0 \cdot 8,3 \cdot 3) \\
-\end{array}$ \\
\hline $\begin{array}{l}\text { Walking } \\
\text { (min/day) }\end{array}$ & $\begin{array}{l}\text { None } \\
1-29 \\
30-59 \\
>59 \\
\text { Test for trend }\end{array}$ & $\begin{array}{r}120 \\
17 \\
29 \\
31\end{array}$ & $\begin{array}{r}149 \\
50 \\
55 \\
128\end{array}$ & $\begin{array}{l}4 \cdot 7 \\
1 \cdot 3 \\
2 \cdot 2 \\
1 \cdot 0 \\
x^{2}=16 \cdot 4 \\
p<0 \cdot 001\end{array}$ & $\begin{array}{l}(2 \cdot 5,8 \cdot 8) \\
(0 \cdot 6,3 \cdot 1) \\
(1 \cdot 1,4 \cdot 3) \\
-\end{array}$ & $\begin{array}{l}3 \cdot 4 \\
1 \cdot 2 \\
2 \cdot 2 \\
1 \cdot 0 \\
\chi_{1}^{2}=8 \cdot 8 \\
p=0 \cdot 003\end{array}$ & $\begin{array}{l}(1 \cdot 7,6 \cdot 8) \\
(0 \cdot 5,2 \cdot 8) \\
(1 \cdot 1,4 \cdot 4) \\
-\end{array}$ \\
\hline Walking speed & $\begin{array}{l}\text { Very slow } \\
\text { Easy pace } \\
\text { Normal } \\
\text { Brisk/fast } \\
\text { Test for trend }\end{array}$ & $\begin{array}{l}61 \\
63 \\
43 \\
28\end{array}$ & $\begin{array}{r}82 \\
121 \\
106 \\
68\end{array}$ & $\begin{array}{l}1 \cdot 7 \\
1 \cdot 3 \\
0 \cdot 8 \\
1 \cdot 0 \\
\chi^{\frac{2}{1}=3 \cdot 5} \\
\mathrm{p}=0.06\end{array}$ & $\begin{array}{l}(0 \cdot 8,3 \cdot 5) \\
(0 \cdot 7,2 \cdot 5) \\
(0 \cdot 4,1 \cdot 6) \\
-\end{array}$ & $\begin{array}{l}1 \cdot 0 \\
1 \cdot 0 \\
0 \cdot 8 \\
1 \cdot 0 \\
\chi^{\frac{2}{1}}=0 \cdot 04 \\
p=0 \cdot 85\end{array}$ & $\begin{array}{l}(0 \cdot 5,2 \cdot 3) \\
(0 \cdot 5,1 \cdot 9) \\
(0 \cdot 4,1 \cdot 6) \\
-\end{array}$ \\
\hline Stair climbing & $\begin{array}{l}\text { Never } \\
\text { Occasionally } \\
\text { Weekly to daily } \\
\text { Several times a day } \\
\text { Test for trend }\end{array}$ & $\begin{array}{r}66 \\
54 \\
22 \\
55\end{array}$ & $\begin{array}{r}73 \\
96 \\
45 \\
168\end{array}$ & $\begin{array}{l}4 \cdot 1 \\
1.9 \\
1 \cdot 3 \\
1 \cdot 0 \\
x^{2}=21 \cdot 5 \\
\mathrm{p}<0 \cdot 001\end{array}$ & $\begin{array}{l}(2 \cdot 2,7 \cdot 7) \\
(1 \cdot 1,3 \cdot 4) \\
(0 \cdot 6,2 \cdot 7) \\
-\end{array}$ & $\begin{array}{l}2 \cdot 7 \\
1 \cdot 6 \\
1 \cdot 0 \\
1 \cdot 0 \\
x_{1}^{2}=8 \cdot 4 \\
\mathrm{p}=0 \cdot 004\end{array}$ & $\begin{array}{l}(1 \cdot 3,5 \cdot 5) \\
(0 \cdot 9,3 \cdot 0) \\
(0 \cdot 5,2 \cdot 3) \\
-\end{array}$ \\
\hline $\begin{array}{l}\text { Productive } \\
\text { activities } \\
\text { (h/week) }\end{array}$ & $\begin{array}{l}<1 \\
1-4 \\
>4 \\
\text { Test for trend }\end{array}$ & $\begin{array}{r}173 \\
19 \\
5\end{array}$ & $\begin{array}{r}289 \\
59 \\
32\end{array}$ & $\begin{array}{l}4 \cdot 2 \\
2 \cdot 1 \\
1 \cdot 0 \\
X_{1}^{2}=10 \cdot 5 \\
p=0 \cdot 001\end{array}$ & $\begin{array}{l}(1 \cdot 4,12 \cdot 9) \\
(0 \cdot 6,7 \cdot 2) \\
\end{array}$ & $\begin{array}{l}3 \cdot 3 \\
2 \cdot 0 \\
1 \cdot 0 \\
\chi_{i}^{2}=6 \cdot 5 \\
p=0 \cdot 01\end{array}$ & $\begin{array}{l}(1 \cdot 1,10 \cdot 2) \\
(0 \cdot 6,6 \cdot 6) \\
-\end{array}$ \\
\hline
\end{tabular}

+ Odds ratio of fracture after adjusting for body mass index, smoking and alcohol consumption.

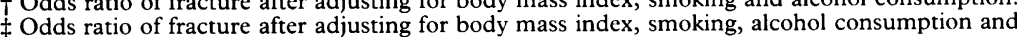
¥ Odds ratio of fracture after adjusting

dependence in daily living activities.

Table III Grip strength and the risk of hip fracture in cases and community controls matched by age and sex*

\begin{tabular}{|c|c|c|c|c|c|c|c|}
\hline Gender & $\begin{array}{l}\text { Grip strength } \\
\text { (kg) }\end{array}$ & $\begin{array}{l}\text { No of } \\
\text { Cases }\end{array}$ & Controls & Odds ratiof & $(95 \%, C I)$ & Odds ratio & $(95 \%, C I)$ \\
\hline Men & $\begin{array}{l}<28 \cdot 0 \\
28 \cdot 0-42 \cdot 3 \\
>42 \cdot 3 \\
\text { Test for trend }\end{array}$ & $\begin{array}{r}17 \\
4 \\
4\end{array}$ & $\begin{array}{l}12 \\
19 \\
18\end{array}$ & $\begin{array}{l}72 \cdot 7 \\
2 \cdot 3 \\
1 \cdot 0 \\
\chi_{1}^{2}=23 \cdot 0 \\
p<0 \cdot 001\end{array}$ & $\begin{array}{l}(2 \cdot 5,2114) \\
(0 \cdot 1,40 \cdot 1)\end{array}$ & $\begin{array}{l}49 \cdot 5 \\
2 \cdot 2 \\
1 \cdot 0 \\
\chi_{1}^{2}=17 \cdot 9 \\
p<0.001\end{array}$ & $\begin{array}{l}(1 \cdot 5,1618) \\
(0 \cdot 1,37 \cdot 5)\end{array}$ \\
\hline Women & $\begin{array}{l}<14 \cdot 3 \\
14 \cdot 3-20 \cdot 0 \\
>20 \cdot 0 \\
\text { Test for trend }\end{array}$ & $\begin{array}{l}75 \\
48 \\
31\end{array}$ & $\begin{array}{r}74 \\
105 \\
117\end{array}$ & $\begin{array}{l}6 \cdot 4 \\
2 \cdot 5 \\
1 \cdot 0 \\
x_{1}^{2}=39 \cdot 1 \\
\mathrm{p}<0 \cdot 001\end{array}$ & $\begin{array}{l}(3 \cdot 0,13 \cdot 7) \\
(1 \cdot 3,4 \cdot 9)\end{array}$ & $\begin{array}{l}5 \cdot 3 \\
2 \cdot 4 \\
1 \cdot 0 \\
\dot{x}_{1}=28 \cdot 3 \\
\mathrm{p}<0.001\end{array}$ & $\begin{array}{l}(2 \cdot 4,11 \cdot 7) \\
(1 \cdot 2,4 \cdot 7)\end{array}$ \\
\hline
\end{tabular}

+ Odds ratio of fracture after adjusting for body mass index, smoking and alcohol consumption ¥ Odds ratio of fracture after adjusting for body mass index, smoking, alcohol consumption and dependence in daily living activities.

* Information was not available for all subjects. the time spent standing each day. The risk of fracture rose with declining reported walking speed, although the trend was not statistically significant $(p=0.06)$ at the $5 \%$ level. The odds ratios were little changed after adjusting for height and weight rather than body mass index, as recommended by Cole and Prentice. ${ }^{12}$ There was a tendency towards steeper increases in risk with declining activity levels in men than women but the number of male cases in each category was small. There was, however, a statistically significant difference in risk gradients for duration of productive activities (test for interaction $\chi_{1}^{2}=6 \cdot 46$, $\mathrm{p}=0.01$ ).

There was a statistically significant $(p<0.001)$ positive association between grip strength and each of the indices of customary physical activity in the controls, after adjustment was made for age and sex. Fracture risk was found to increase steeply, and statistically significantly $(p<0.001)$, with decline in grip strength (table III), a relationship which persisted in both sexes after allowing for body mass index, alcohol consumption, and cigarette smoking.

To explore the extent to which the customary activity of the elderly population might be amenable to modification, we examined the influence of activity level and muscle strength on fracture risk after adjusting for the three previously listed potential confounders as well as the level of disability as assessed by a Katz scale of daily living activities. ${ }^{13}$ Subjects requiring help in one or more daily living activities (30\% of total) had an increased risk of hip fracture (odds ratio $=3 \cdot 6,95 \%$ CI $2 \cdot 1,6 \cdot 2)$. These subjects also had lower levels of customary activity for all five indices and lower grip strength, after adjusting for age and sex. Tables II and III show that even after taking established disability into account, the activity level was significantly associated with fracture risk, for all activities except walking speed. There was a tendency, towards steeper increases in risk with declining levels of activity among subjects who were fully independent, compared with those requiring help in one or more activities. These differences in risk gradients however were not statistically significant at the $5 \%$ level. The relationship between grip strength and fracture risk was also changed little by adjustment for disability.

\section{Discussion}

The results of this study confirm the previously reported associations between customary physical inactivity, muscle weakness and the risk of hip fractures among elderly people in Britain. ${ }^{5}$ There was a steep increase in fracture risk with declining levels in four of five validated indices of physical activity. This relationship was stronger in men than in women, but the number of male cases was small, and risk estimates were therefore imprecise.

The study included only patients who were able to score six or more on a 10 point Hodkinson abbreviated mental test score. ${ }^{9}$ This is a widely used mental test procedure which relies on 10 questions of orientation and memory which have been derived from the longer Roth-Hopkins test. ${ }^{14}$ The 10 questions enquire about age, time, year, name of institution, recognition of another 
person, date of birth and four recall items for short and long term memory. The long Roth-Hopkins test which contains some 29 items, has been shown to correlate well with the pathological changes of senile dementia, ${ }^{15}$ but is a rather unwieldy tool with which to classify mental impairment in the elderly. The abbreviated version which was used in this study has been shown to correlate well with both the longer Roth-Hopkins test, as well as the modified Tooting-Beck questionnaire, another widely used assessment method for mental impairment. ${ }^{9}$ The reason why this mental test score was used to screen for dementia in our study, was that piloting of the activity questionnaire suggested that intellectual deterioration at a particular threshold on this questionnaire reduced the validity of physical activity information obtained. Although the same selection criterion was applied to controls, a greater proportion of potential cases (35\%) than of potential controls ( $12 \%)$ was excluded on this basis. As the activity levels of demented elderly people are likely to be lower than those who are mentally fit, any bias introduced into our study as a result of this selection criterion would tend to reduce the relative risks observed, rather than magnify them. The measurement of physical activity poses a considerable problem in epidemiological research. ${ }^{16} \mathrm{We}$ adopted a method which has been stringently evaluated for use in the elderly, ${ }^{10}$ and combined this with a measurement of isometric muscle strength.

The risk of hip fractures in the elderly depends upon bone strength and the likelihood of falling. ${ }^{2}$ There is evidence that physical inactivity and muscle weakness influences both these pathogenetic mechanisms. Several studies have documented the effects of exercise on bone density measured at various skeletal sites, ${ }^{3}{ }^{17}$ and muscle weakness is a known risk factor for falls in the elderly. ${ }^{18}$ Only recently, however, has direct evidence become available that inactivity is a risk factor for hip fracture. Two case-control studies have reported that inactivity during youth and middle life is a risk factor for subsequent hip fracture, ${ }^{19} 20$ suggesting that promotion of exercise during these periods of life seems a prudent public health strategy. Several decades would be required, however, before such a policy could be expected to result in a decline in the overall incidence of hip fractures, as most of these occur after the age of 75 years. Furthermore, the skeletal benefits obtained by high activity levels in middle life may not persist if such activity is not maintained through to older ages. Promotion of moderate weight-bearing exercise among the elderly provides a more immediate, albeit complementary, strategy. It is possible, however, that inactivity among elderly people is consequent upon illness or locomotor disability, and that efforts to promote exercise in such individuals are impractical. Our observation that the relationship between inactivity and fracture risk remains after adjusting for dependence in daily living activities, a marker of general disability, and tended to be strongest in individuals who were fully independent, suggests that in a substantial section of the elderly population, such a public health strategy may be expected to yield dividends. The precise nature and duration of such programmes remain to be evaluated in further clinical and epidemiological studies, but our results point to the importance of simple, weight-bearing activities.

Directly measured hip fracture incidence rates derived in Newcastle upon Tyne in $1986,{ }^{8}$ were higher than those calculated over a similar period in Southampton. ${ }^{21}$ Comparison of the activity levels among the control groups included in the Southampton and Newcastle upon Tyne studies suggests that regional variation in activity patterns among the elderly does not account for this variation. In conclusion, this study confirms that physical inactivity and muscle weakness are both associated, independently of other influences, with an increased risk of hip fracture in elderly people. Our findings point to the importance of exploring ways of maintaining activity in our ageing population.

We thank the consultants and staff of the department of Orthopaedic Surgery, Royal Victoria Infirmary and Newcastle General Hospital, as well as Mrs K Cowin who interviewed all the cases and controls.

1 Royal College of Physicians of London. Fractured neck of femur: prevention and management. London: Royal College of Physicians, 1989.

2 Cooper C, Barker DJP, Morris J, Briggs RSJ. Osteoporosis, falls and age in fracture of the proximal femur. BMf 1987 295: 13-15.

3 Smith EL, Raab DM. Osteoporosis and physical activity. Acta Med Scand 1986; Suppl. 711: 149-156.

4 Chow R, Harrison JE, Notarius C. Effect of two randomised exercise programmes on bone mass of healthy postmenopausal women. BMF 1987; 295: 1441-4.

5 Cooper C, Barker DJP, Wickham C. Physical activity, muscle strength and calcium intake in fracture of the proximal femur in Britain. BMF 1988; 297: 1443-6.

6 Lau EMC, Donnan S, Barker DJP, Cooper C. Physical activity and calcium intake in fracture of the proximal femur in Hong Kong. $B M 7$ 1988; 297; 1441-3.

7 Evans JG. A prospective study of fractured proximal femur: incidence and outcome. Public Health 1979; 93: 235-41.

incidence and outcome. Public Health 1979; 93: 235-41.
Wood DJ. Incidence and mortality of femoral neck fractures. Wood DJ. Incidence and mortality of femoral

9 Quereshi KW, Hodkinson HM. Evaluation of a ten question mental test in the institutionalised elderly. Age Ageing 1974 3: $152-7$

10 Dallosso HM, Morgan K, Bassy EJ, Fentem PH, Arie TDH Levels of customary physical activity among the old and very old living at home. $\mathcal{F}$ Epidemiol Community Health 1988; 42 121-7.

11 Breslow NE, Day NE. Conditional logistic regression for matched sets. In: Breslow NE, Day NE, eds Statistical methods in cancer research. Vol 1. The analysis of case-control Vor Research on studies. Lyons: Internation

12 Cole TJ, Prentice A. Bone mineral measurements. BMF 1992; 305: 1223-4. (Letter).

13 Katz S, Ford AB, Moskowitz RW, Jackson BA, Jaffe MW. Studies of illness in the aged: the index of ADL: a Studies of illness in the aged: the index of ADL: a
standardised measure of biological and psychosocial standardised measure of biological

14 Roth M, Hopkins B. Psychological test performance in patients over 60 . I. Senile psychosis and affective disorders patients over 60. I. Senile psychosis and affective disorders
of old age. Fournal of Mental Sciences 1953; 99: 439-50.

15 Blessed G, Tomlinson BE, Roth $M$. The association between qualitative measures of dementia and senile changes in the grey matter of elderly subjects. Br f Psychiatry 1968; 114: $797-811$

16 LaPorte RE, Montoye HJ, Caspersen CJ. Assessment of physical activity in epidemiologic research: problems and prospects. Public Health Rep 1985; 100: 131-46.

17 Smith EL, Gilligan C. Physical activity effects on bone metabolism. Calcif Tissue Int 1991; 49 (Suppl): S50-4.

18 Wickham C, Cooper C, Margetts BM, Barker DJP. Muscle strength, activity, housing and the risk of falls in the elderly. Age Ageing 1989; 18: 47-51.

19 Cooper C, Wickham C, Coggon D. Sedentary work in middle life and fracture of the proximal femur. $\mathrm{Br} \mathcal{F}$ Industrial Medicine 1990; 47: 69-70.

20 Boyce WJ, Vessey MP. Habitual physical inertia and other actors in relation to risk of fracture of the proximal femur. Age Ageing 1988; 17: 319-27.

21 Lau EMC, Cooper C, Wickham C, Donnan S, Barker DJP. Hip fracture in Hong Kong and Britain. Int $\mathcal{f}$ Epidemiol 1990; 19: 1119-21. 